\title{
Acil Serviste Renal Kolik Öntanısı Alan Hastaların Demografik ve Klinik Özellikleri
}

\author{
${ }^{1}$ Filiz Baloğlu Kaya, ${ }^{1}$ Arif Alper Çevik, ${ }^{1}$ Nurdan Acar, ${ }^{2}$ Şeyhmus Kaya, \\ ${ }^{2}$ A.Tuğrul Zeytin \\ ${ }^{1}$ Eskişehir Osmangazi Üniversitesi Tıp Fakültesi Acil Tıp Anabilim Dalı, \\ ${ }^{2}$ Eskişehir Devlet Hastanesi \\ e-posta: fbaloglu@ hotmail.com
}

\begin{abstract}
ÖZET: Amaç: Renal kolik (RK) acil servislerde (AS) tanı ve tedavisi yapılan en sık, en ağrılı ürolojik acil durumdur. Bu çalışmada bir üniversite hastanesi AS'sinde RK ön tanısı alan hastaların demografik ve klinik özellikleri araştırıldı. Gereç-Yöntem: 11 aylık sürede AS'ye kolik tipte yan ağrısı ile başvuran, 18-65 yaş arası, idrar yaparken yanma veya idrar renginde değişiklik tarifleyen, son 12 saat içinde ağrı veya bulantı giderici ilaç kullanmamış olan, klinik olarak RK ön tanısı alan, çalışmada yer almayı kabul eden hastalar alındı. Hastaların yaş, cinsiyet, özgeçmiş/ soygeçmiş özellikleri,sıvı tüketimi, AS'ye başvuru anındaki ağrı, bulantı, kusma durumu ve başvuru zamanları kaydedildi. AS ve 1ay sonraki Üroloji poliklinik değerlendirmesinde aldıkları

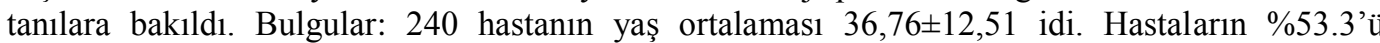
erkekti. Gün içinde en çok saat 13:01-14:00 arasında, en sık mayıs ayında başvuru oldu. Hastaların \%33,1'inin özgeçmişinde, \%21,9'unun ailesinde taş hikayesi vard1. Hastaların \%52,5'inde günlük Sıv1 tüketimi 1-2,5 litreydi. VAS'a göre bulantı düzeyi ortalaması $20.26 \pm 28.69 \mathrm{~mm}$, ağrı düzeyi ortalaması $68.90 \pm 25.55 \mathrm{~mm}$ bulundu. Hastaların \%91,3'ünde kusma yoktu. AS'de $221(\% 91,3)$ hasta, Üroloji polikliniğinde 41 hasta (polikliniğe başvuran hastaların \%69,4'ü) ürolitiyazis tanısı aldı. Sonuç: AS'ye başvuran RK hastalarının özelliklerinin belirlenmesi erken tanı ve tedavinin önemli olduğu bu tip hastalarda yararlı olacaktır.
\end{abstract}

ANAHTAR KELIMELER: renal kolik, acil, demografik özellikler

SUMMARY: Objective: Renal colic (RC) is the most frequently diagnosed and treated urgent condition, which is described as the worst pain ever experienced, at emergency department (ED). In this study, the demographic and clinical profiles of the patients pre-diagnosed with RC at the ED of a university hospital were examined. Methods: The study includes the patients, who came to the ED with a colicky pain on the side(s) in a period of 11 months. The patients were between ages 18 and 65, described burning with urination or change of color in their urine, did not take any pain or nausea medication within the last 12 hours, are clinically pre-diagnosed as renal colic and singed the informed consent. The age, gender, histories, family histories, and fluid intake of the patients were recorded alongside their condition of pain, nausea, vomiting when they first came to the ED and the time which they presented to the ED. Their diagnoses at the ED and the ones at the Urology outpatient clinic, which was performed 1 month later, were examined. Results: The average age of 240 patients was $36,76 \pm 12,51.53 .3 \%$ of patients were male. The most frequent presentation of patients at the ED was the hours between 13:01 and 14:00 during the day and in May during the periot of the study. $33.1 \%$ of patients had history of stones and $21.9 \%$ had family history of stones. $52.5 \%$ of the patients had 1 to 2.5 liters of fluid intake. VAS for average nausea level was $20.26 \pm 28.69 \mathrm{~mm}$ and average pain level was $68.90 \pm 25.55 \mathrm{~mm} .91 .3 \%$ of the patients had no vomiting. 221 patients $(91.3 \%)$ at the ED and 41 patients $(69.4 \%$ of patients presented to the outpatient clinic) at the Urology outpatient clinic were diagnosed as urolithiasis. Conclusion: Determining profiles of patients, who came to ED with RC, will be useful in the early diagnoses and treatment of such patients.

KEY WORDS: Renal colic, emergency, demographic features

Giriş: Renal kolik (RK) sıklıkla üriner sistem taş hastalığına bağlı gelişen klinik bir tablodur. Acil servislerde (AS) tanı ve tedavisi yapılan en s1k ve de en ağrilı ürolojik acil durumdur $(1,2)$. Üriner taş hastalığı tıp arşivlerinde oldukça uzun bir geçmişe sahiptir. Bu konuda ülkemizde yeterli kayıt ve istatistiki bilgi bulunmamakla

birlikte,

Kuzey Amerika'da yılda 1 milyondan fazla RK nedenli AS başvurusu yapılmakta ve Avrupa'da acil ambulans aramalarının \%7-9'unu RK oluşturmaktadır (1). Ağrı, bulantı ve kusma varlığı nedeni ile erken dönemde tan1 konması ve tedavi başlanması hasta konforu açısından 
önemlidir. Hastaların demografik özellikleri, anamnez ve klinik özellikleri erken tanıda ve tedavi sürecinin hızlanmasında hekimlere yardımcı unsurlardır. Bu nedenle çalışmamızda bir üniversite hastanesi acil servisine kolik tipte yan ağrısı ile başvuran ve klinik olarak renal kolik öntanısı alan hastaların demografik ve klinik özelliklerini araştırdık.

\section{Gereç ve Yöntem:}

21.04.2008- 25.02.2009 tarihleri arasında ESOGÜ Tıp Fakültesi Hastanesi Acil Servisi'ne kolik tipte yan ağrısı şikayeti ile başvuran 18- 65 yaş arası, idrar yaparken yanma ya da idrar renginde değişiklik tarifleyen, son 12 saat içinde ağrı kesici ya da bulantı giderici ilaç kullanmamış olan, klinik olarak renal kolik ön tanısı alan, "Hasta Bilgilendirme Formu" ve "Hasta Onam Formu" okutularak imzalı onamları ile çalışmada yer almayı kabul eden hastalar alındı. Hastaların yaş, cinsiyet, özgeçmiş ve soygeçmiş özellikleri, sıvı tüketimi, acil servise başvuru anındaki ağrı ve bulantı Visual Analog Scale (VAS) ortalamaları, kusma varlığı ve AS başvuru zamanı kayıtları alındı. AS değerlendirme süreci sonunda hastaların aldıkları tanılara bakıld1. Hastalara AS'den taburculuk sonrası control amaçlı Üroloji polikliniğine başvurmaları önerildi. AS başvurusundan sonraki 1 ay içinde dosya kayıtları incelendi. Hastaların poliklinik değerlendirme sonuçlarına bakıldı. Çalışmadan elde edilen veriler "Statistical Package for the Social Sciences" (SPSS)13 programı ile değerlendirildi. Sayısal değişkenler ortalama \pm standart sapma, kategorik değişkenler sayı ve yüzde olarak özetlendi. İstatiksel analizde $\chi^{2}$ testi kullanıldı ve $p<0.05$ değeri anlamlı kabul edildi.

Bulgular: Çalışma sürecinde klinik olarak renal kolik tanısı alan ve çalışmanın dahil edilme kriterlerine uyan 240 hasta tespit edildi ve çalışma grubunu oluşturdu. Çalışmaya dahil edilen hastaların 128'inin (\%53.3) erkek, 112'sinin (\%46.7) kadın olduğu saptand1. Hastaların yaş ortalaması $36,76 \pm 12,51$ idi (uç değerler: 18-65). Olguların yaş gruplarına göre dağılımı Şekil 1'de verilmiştir.

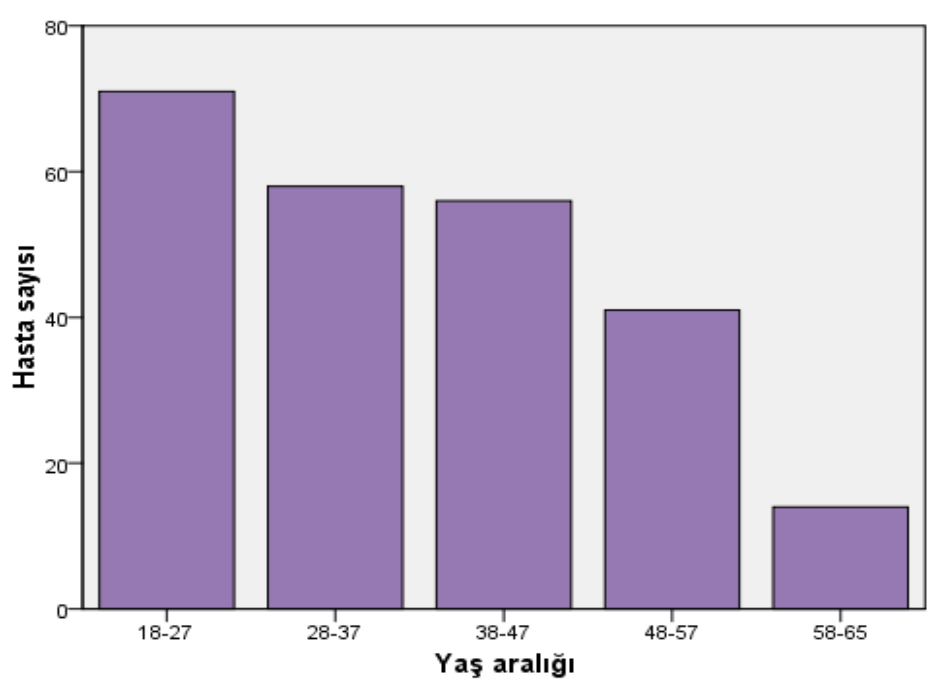

Şekil 1: Olguların yaş gruplarına göre dağılımı.

Hastaların AS'ye geliş zamanlarına Eylül ayında $31(\% 12.9)$ hasta ile en fazla bakıldığında Mayıs ayında 36 (\%15), başvurunun yapıldığı görüldü. Bu durum 
istatistiksel olarak da anlamlı bulundu başvurdukları aylara göre dağılımı Şekil $(\mathrm{p}=0,003)$. Hastaların acil servise 2'de gösterilmiştir.

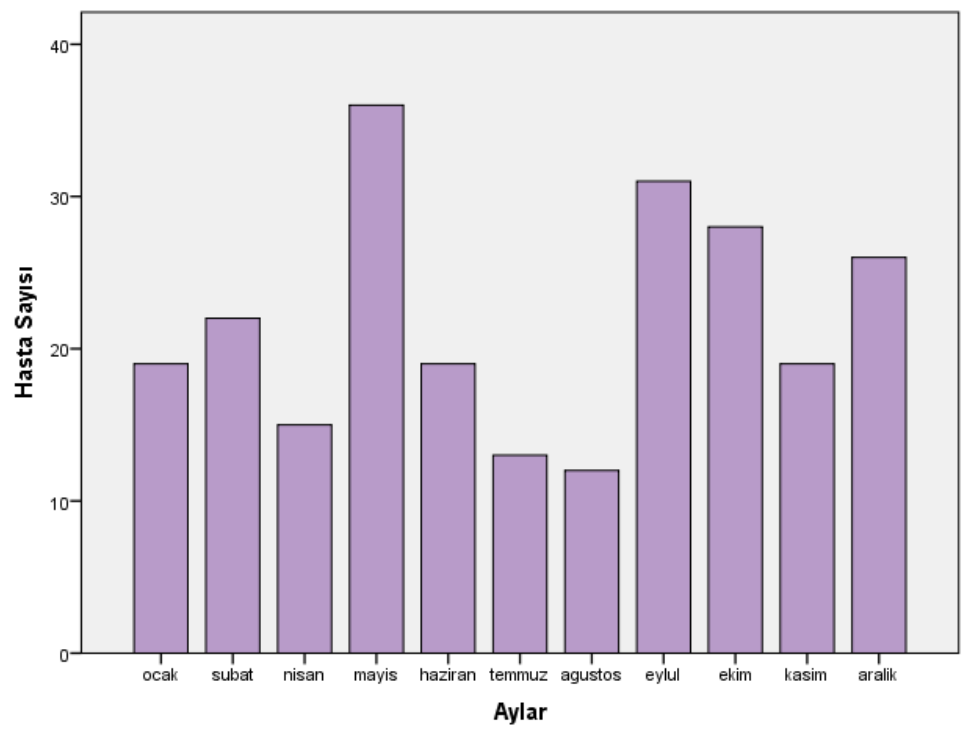

Şekil 2: Olguların başvuru aylarına göre dağılımı.

Hastaların gün içinde AS'ye başvuru $(p>0,05)$. Hastaların acil servise başvuru saatlerine bakıldığında ise istatistiksel saatlerinin dağılımı Şekil 3'de olarak anlamlı bir fark saptanmadı gösterilmiştir.

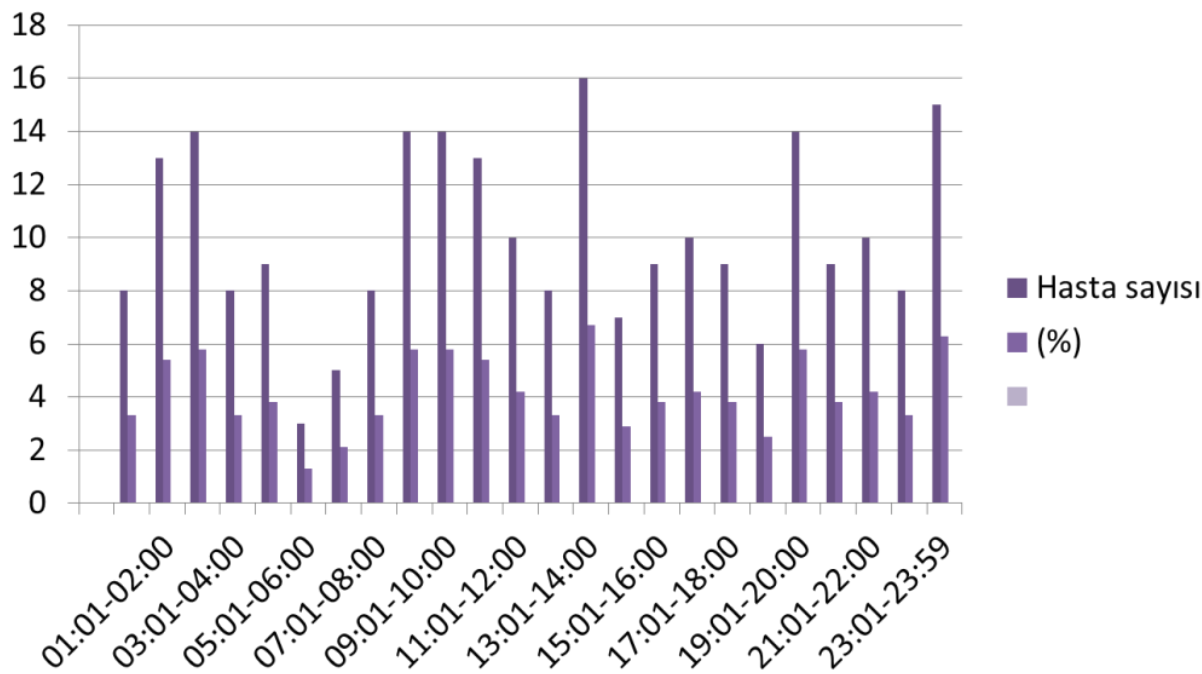

Şekil 3: Olguların başvuru saatlerine göre dağılımı. 
Hastaların özgeçmişinde üriner sistem taş hastalığı hikayesi sorgulandığında, 160 $(\% 66,1)$ hastada özellik olmadığı, 80 $(\% 33,1)$ hastada ise daha önceye ait taş hastalığı hikayesi olduğu görüldü (Şekil
4). Ailede taş hastalığı varlığına bakıldı. $187(\% 77,3)$ hastanın aile öyküsünde özellik yoktu. $53(\% 21,9)$ hastada ise ailevi taş öyküsü olduğu görüldü (Şekil 5).

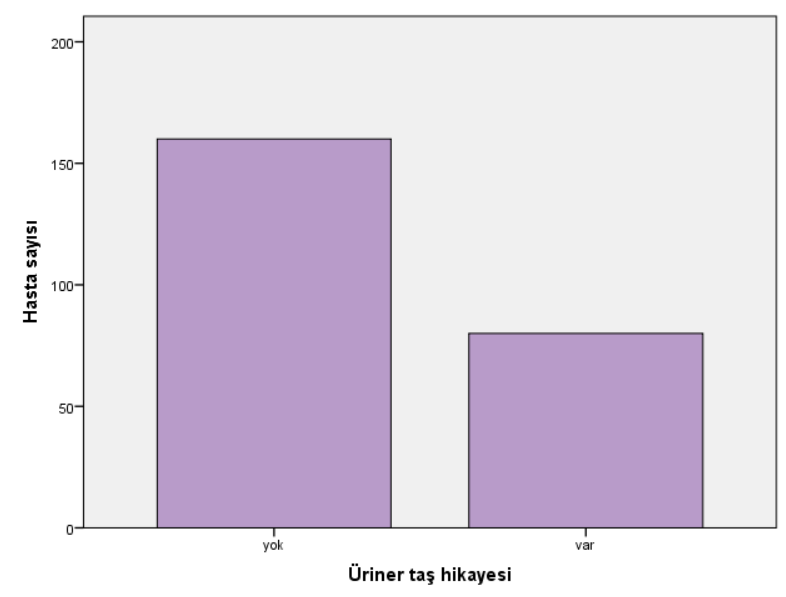

Şekil 4: Olguların özgeçmişinde üriner sistem taş hastalığı varlığı

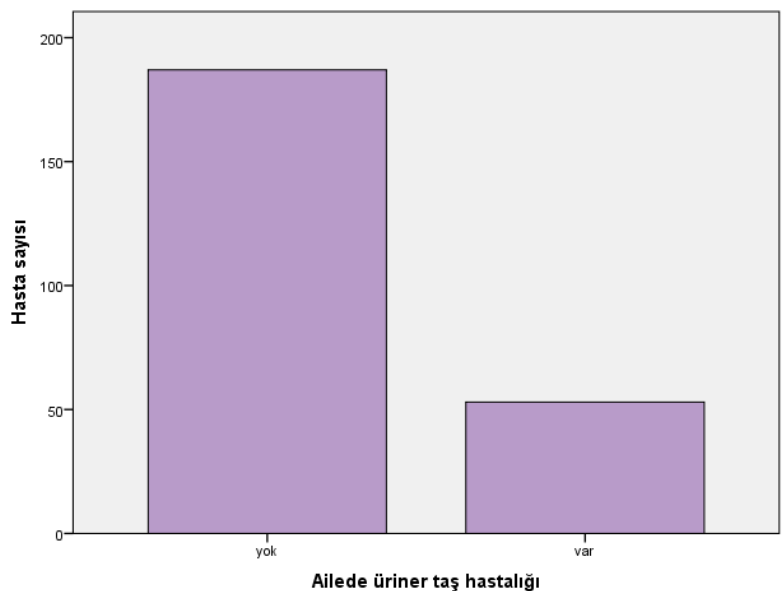

Şekil 5: Olguların aile hikayesinde üriner sistem taş hastalığı varlığı

Hastaların günlük sıv1 tüketimi $(\% 14,0)$ hastanın ise 2,5 litreden fazla sıv1 sorgulandı. $79(\% 32,6)$ hastanın 1 litreden alımı olduğu belirlendi (Şekil 6). az, $127(\% 52,5)$ hastanın 1-2,5 litre, 34 


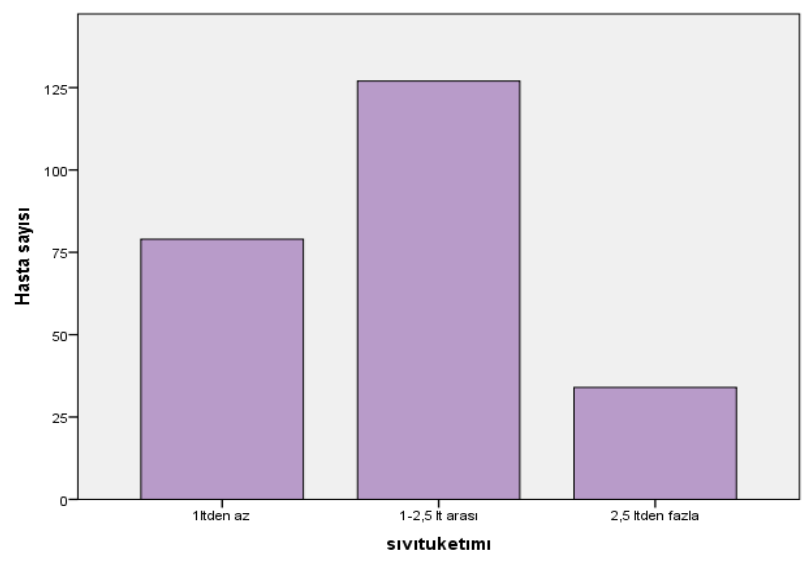

Şekil 6: Olguların günlük sıvı tüketimi

Hastaların başvuru anında klinik kolik, $19(\% 7,9)$ hastaya ise idrar yolu yakınmalarına bakıldı. VAS'a göre bulantı enfeksiyonu ve nonspesifik karın ağrısı düzeyi ortalaması $20.26 \pm 28.69 \mathrm{~mm}$ (uç değerler: 0-100) bulundu. VAS'a göre ağrı düzeyi ortalaması ise $68.90 \pm 25.55$ mm ( uç değerler: 5-100) olarak saptandi. Hastaların $221 \quad(\% 91,3)$ 'inde başvuru anında kusma yok iken, $19(\% 7,9)$ 'unda kusma şikayeti olduğu görüldü.

Hastaların hiç birinde tedavi gerektiren tansiyon arteriyel düşüklüğü ya da yüksekliği, vücut 1sısı anormalliği, nabız ve solunum sayısında değişiklik saptanmadi.

tanılarının konulduğu saptandı.

Hastaların 1 ay sonra dosya kayitlarından yapılan değerlendirmede 240 hastanın 181'inin (\%75) önerilen Üroloji poliklinik kontrolüne gitmediği görüldü. Üroloji polikliniğine başvuran hastaların ise $41^{\prime}$ inde $(\% 69,4)$ ürolitiyazis tanısının netleştirildiği, 6'sının $(\% 10,1)$ ürolitiyazis dışında bir tanı aldığ görüldü. 12 hastanın $(\% 20,3)$ ise sonucunun henüz netleşmediği belirlendi (Şekil 7). Ürolitiyasiz tanısı netleşen hastaların 29' unun $(\% 70,7)$ erkek olduğu saptand1.

AS takip ve tedavi süreci sonunda 221 $(\% 91,3)$ hastaya son tanı olarak renal

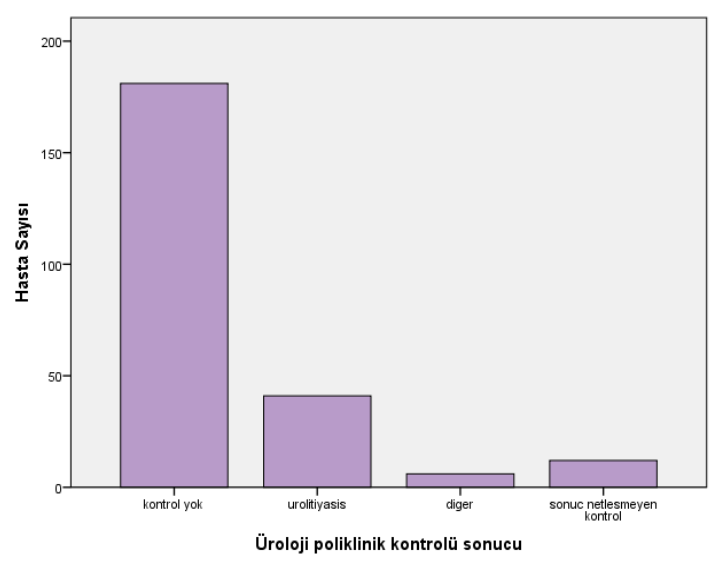

Şekil 7: Olguların üroloji poliklinik kontrol sonucu değerlendirmesi. 
Tartışma: RK sıklıkla böbrek taş hastalığına bağlı gelişir ve AS'ye en sık ürolojik başvuru nedenidir $(1,2)$. Hastalar tarafından yaşadıkları en ağrı verici, zayıf düşürücü tecrübe olarak tarif edilir (1). Taşlar yan ağrısı ya da hematüriye neden olacak büyüklüğe ulaştıklarında semptomatik hale gelirler. RK atakları 3 . ve 5. dekadda sik olarak literatürde yer alırken (3), Chauhan ve ark.' '1n yaptı̆̆ 13,5 milyon olgudan oluşan ve 30.358 RK tanısı içeren veri tabanı taramasında yaş ortalaması $44 \pm 14$ olarak saptanmıştır (4). Bizim çalışma grubumuzda da literatürle benzer şekilde yaş ortalaması 36,76 \pm 12,51 bulundu. Literatüre bakıldığında RK erkeklerde 3 kat daha fazla görülmekle $(3,5)$ birlikte, Türkiye'de yapılan ve üriner taş hastalığı insidansını \%15 olarak belirleyen bir çalışmada da erkek: kadın oranı 1,5:1 şeklinde bulunmuştur (6). Bizim çalışmamızda da bu oran benzer şekilde erkeklerde 1,27 kat fazla olarak bulunmuştur. Sicak mevsimlerde daha sik başvuru beklenirken (4,7-9) bizim çalışmamızda sırası ile $36(\% 15)$ ve 31 $(\% 12,9)$ hasta ile en çok başvuru mayıs ve eylül ayında yapılmıştır. Bulgularımız, seyahat ya da yaz aylarında farklı bölgelerde yaşama gibi nedenlerle değisşen nüfus dağılımından etkilenmiş olabilir. Çalışma AS dışında kalan sağlık kuruluşlarına başvuran RK vakalarını kapsamadığ1 için de değerlendirme sonuçları etkilenmiş olabilir. Yine gece boyunca idrar üretiminin azalması nedeni ile sabah saatlerinde daha sik başvuru beklenirken (7) bizim çalışmamızda başvuru saati açısından gün içi dağılımda fark bulunmamıştır.

Tüm yaşamı boyunca bir kişinin RK atağ 1 geçirme riski \%1-10 iken, 5 yıl içinde tekrar etme oranı ise yaklaşık \%50'dir $(1,2,7,10)$. Semptomların ortaya çıkmasında ve atakların yinelemesinde diyet alışkanlıkları önemlidir. Amerikan Üroloji Derneği ve Avrupa Üroloji Derneği kılavuzlarında tekrarlama riskini önlemede bu konuda öneriler sunulmuştur $(11,12)$.

$\mathrm{Bu}$ önerilerden birisi 24 saatlik idrar miktarı 2,5 litre ve üzerinde olacak şekilde yüksek miktarda sıv1 tüketilmesidir (Kanıt Düzeyi 1b; Öneri Sınıfı A). Aşırı su alımı idrar volümünü artırarak dilüe idrar oluşumunu ve diürezi arttırmaktadır. Sonuç olarak kristaller üriner yapıları daha hızlı terk edip taş oluşumu engellenmektedir. Literatürde idrar volümünün azalması sonucu idiyopatik kalsiyum taşı sıklığının arttığı da belirtilmektedir $(3,13,14)$. Tek başına yeterli sıvı alımı dahi üriner sistem taş hastalığı oluşum ve tekrarlama risklerini azaltabilmektedir (15-17). Bu nedenlerle hastalarda günlük sıvı tüketimi sorguland. $79(\% 32,6)$ hastanın 1 litreden az, 127 $(\% 52,5)$ hastanin 1-2,5 litre, $34(\% 14,0)$ hastanın ise 2,5 litreden fazla sıv1 alımı olduğu belirlendi. Önceye ait taş hikayesi olan 80 hastada siv1 tüketimine bakıldığında çok azının $(\% 12,5)$ yeterli su içtiği görüldü. Çalışma grubundaki hastaların yeterli sıv1 alımına dikkat etmedikleri, bu konuda bilgilendirilmelerinin daha iyi yapılması gerektiği sonucuna ulaşıldı.

Taş hastalığında polijenik gen defektleri, ailesel renal tubüler asidoz, sistinüri, ksantinüri göze çarpan nadir kalıtsal hastalıklardır (18). Değişik serilerde taş hastalarının ailelerinde $\% 12.5$ ile $\% 37$ arasında değişen ürolithiyazis hikayesi mevcut olduğu bildirilmektedir (19). Tekrarlayan RK'l1 hastaların \%25'inde ailede üriner sistem taş hastalığ 1 hikayesi bildirilmiştir $(7,8)$. Bizim hastalarımızda da bu oran literatürle uyumlu olarak $\% 21,9$ bulundu.

Üriner sistem taşı olan hastalarda belirti ve bulgular taşın boyutuna, yerine, pozisyonuna, infeksiyon gibi komplikasyonların mevcudiyetine bağlı olarak değişiklik gösterebilir. Bazı hastalarda yan ağrısı tek başına belirti iken buna hematuri, üriner enfeksiyon var ise 
dizüri, sık idrar yapma isteği ve de ateş eklenebilir. Bazı renal taşlar ise asemptomatik olabilir. Hastalar acil servise sıklıkla dayanılmaz ağrı ve şiddetli stres hali ile başvururlar. Bulantı ve kusma bu grup hastalarda yaklaşık \% 50 oranında görülmektedir. Başvuru anında hastaların 98 'i $(\% 40,5)$ bulantı tariflemiyordu. VAS'a göre bulantı düzeyi ortalaması 20.26 $28.69 \mathrm{~mm}$ (uç değerler: 0-100) bulundu. Hastaların 221 (\%91,3)'inde başvuru anında kusma yok idi. VAS'a göre ağrı düzeyi ortalaması ise $68.90 \pm 25.55 \mathrm{~mm}$ (uç değerler: 5-100) olarak saptandi.

Acil hasta değerlendirmesinde vital bulguların yeri önemlidir. Tespit edilen anormallikler acil müdahale gerektiren durumlara işaret edebilir. Çalışma grubumuzdaki hastaların hiç birinde tedavi gerektiren tansiyon arteriyel düşüklüğü ya da yüksekliği, vücut 1sıs1 anormalliği, nabız ve solunum sayısında değişiklik saptanmadi.

RK dışı tanı alan 19 hastanın idrar yolu enfeksiyonu tanısı aldığı ve bunların 15' inin $(\% 78,9)$ kadın olduğu görüldü. $\mathrm{Bu}$ durum literatür ile de uyumlu olarak değerlendirildi (4). Kadınlarda ürogenital anatomik yap1 enfeksiyon riskini arttırmakta ve kişisel hijyen de bu konuda önemli rol oynamaktadır.

RK tedavisinde başarı hasta uyumu ile sağlanır. Bizim çalışmamızda hastalara AS'den taburculuğu sonrasinda Üroloji poliklinik kontrolüne gitmeleri önerilmiştir. Ancak 1 ay sonraki dosya kayıt değerlendirmelerinde hastaların \%75'inin kontrole gitmediği tespit edilmiştir. Bu akut ağrısı için hastanemiz AS'sini tercih eden hastaların elektif şartlarda başka sağlık kuruluşlarını tercih etmelerinden ya da randevu sistemi nedeni ile mecburen başka merkezlerde yaptırmalarından da kaynaklanmış olabilir. Poliklinik kontrolleri ile ürolitiyazis tanısı netleșen 41 hastaya bakıldığında 29'unun $(\% 70,7)$ literatürle uyumlu olarak erkek olduğu saptandı $(3,5)$.

Sonuç: Çalışmamızda acil servise başvuran ve klinik olarak renal kolik tanısı alan hastalar ile ilgili demografik ve klinik veriler elde edilmiştir. Bölgemizde bulunan bu grup hastaların özelliklerinin tanınması hem koruyucu hem de tedavi edici yaklaşımlar açısından acil hekimlerine kolaylık sağlayacaktır.

\section{KAYNAKLAR}

1. Müslümanoğlu, A.Y. Tepeler, A. (2008). Renal kolik, tanı ve tedavisi. Marmara Medical Journal. 21(2):18792.

2. Koçak, D. (2007). Kolik renal ve akut obstrüksiyonlar. Türkiye Klinikleri J Surg Med Sci. 3(20):3-8.

3. Engineer, R. Peacock, W.F. Urologic stone disease. In: Tintinalli, J.E. Kelen, G.D. Stapczynski, J.S. editors. (2004). Emergengy medicine: a comprehensive study guide. 6th ed. New York: McGraw- Hill.p.620-5.

4. Chauhan, V. Eskin, B. Allegra, J.R. Cochrane, D.G. (2004). Effect of season, age and gender on renal colic incidence. $A m j$ Emerg Med. 22(7):560-63.

5. Fetter, T.L. Zimskind, P.D. (1961). Statistical anallysis of patient with urinary calculi. JAMA.186:21.

6. Akıncı, M. Esen, T. Tellaloğlu, S. (1991). Urinary stone disease in Turkey: an updated epidemiological study. Eur Urol. 20:200-3.

7. Esquena, S. Rodriquez, M. SanchezMartin, F.M. et al. (2006). Renal colic: Literature review and scientific evidence. Actas Urol Esp. 30(3):26880 . 
8. Ljunghal, S. Danielson, B.G. Fellstrom, B, et al. (1985). Family history of renal stones in recurrent stone patients. Br. J. Urol.57(4):370-4.

9. Al-Hadramy, M.S. (1997). Saesonal variations of urinary stone colic in Arabia. J Pak. Med. Assoc.47:281-4.

10. Shokeir, A.A. (2002). Renal colic: new concepts releted to pathophysiology, diagnosisand treatment. Current Opinion in Urology.12:263-9.

11. Pearle, M.S. Goldfarb, D.S. Assimos, D.G. et al. (2014). Medical management of kidney stones: AUA guideline. J Urol. Aug. 192(2):316-24. doi: 10.1016/j.juro.2014.05.006.

12. Skolarikos, A. Straub, M. Knoll, T. et al. (2014). Metabolic Evaluation and Recurrence Prevention for Urinary Stone Patients: EAU Guidelines. Eur Urol. Nov 20. pii: S03022838(14)01102-6. doi: 10.1016/j.eururo.2014.10.029.

13. Parmar, M.S. (2004). Kidney stones. Clinical review. BMJ. 328:1420-4

14. Hamm, M. Wowroschek, F. Weckermann, D. et al. (2001).

Unenhanced helical computed tomography in the evaluation of acute flank pain. Eur. Urol. 39:460-5

15. Hosking, D.H. Erickson, S.B. Van Den Berg, C.J. et al. (1983). The stone clinic effect in patients with idiopathic calcium urolithiasis. J Urol 130:11151118

16. Borghi, L. Meschi, T. Schianchi, T. et al. (1999). Urine volume: Stone risk factor and preventive measure. Nephron 81: 31-37

17. Borghi, L. Meschi, T. Amato, F. et al. (1996). Urinary volume, water and recurrences in idiopathic calcium nephrolithiazis: A 5-year randomized prospective study. J Urol. 155:839843.

18. Danpure, C.J.(2000). Genetic disorders and urolithiasis. Urol Clin North Am. 27:287-299.

19. Tefekli, A. Tok, A. Altunrende, F. Barut, M. Berberoğlu, Y. Müslümanoğlu, A.Y. (2005). Üriner sistem taş hastalarında yaşam tarzı ve beslenme alışkanlıkları. Turkish $J$ Urology. 31: 113-118. 